\title{
SOME DIFFERENCE INEQUALITIES WITH WEIGHTS AND INTERPOLATION
}

\author{
LARS-ERIK PERSSON AND AlOIS KUFNER
}

\begin{abstract}
The well-known Grisvard-Jakovlev inequality (see Theorems 1 and $1^{\prime}$ ) can be interpreted as a fractional order Hardy inequality or as a weighted difference inequality. Some inequalities of this type have been recently proved and discussed by the authors and H. Heinig, and this paper coincides mostly with a lecture held by the first author at the International workshop on difference and differential inequalities (July 3 - 7, 1996, Marmara Research Center, Turkey) where some historical remarks, ideas and results from the papers of the authors and $\mathrm{H}$. Heinig have been presented. Additionally we present and prove some new difference inequalities with weights. Mostly, we omit the proofs which can be found in the papers mentioned and in the references there, and for simplicity, we consider functions on the interval $(0, \infty)$.
\end{abstract}

Mathematics subject classification (1991): 26D15, 46E30.

Key words and phrases: Inequalities, difference inequalities, fractional order derivatives, Hardy inequalities, weight functions, $L^{p}$-spaces, mixed norm spaces, real interpolation.

\section{REFERENCES}

[1] V. I. BuRENKov, W. D. Evans, Weighted Hardy-type inequalities for differences and the extension problem for spaces with generalized smoothness, J. London Math. Soc. (to appear).

[2] H. P. Heinig, A. Kufner, L.-E. Persson, On some fractional order Hardy inequalities, J. Inequalities and Applications 1 (1997), 25-46.

[3] A. KUfNER, L.-E. PERSSON, Hardy inequalities of fractional order via interpolation, Inequalities and applications (R. P. Agarwal, ed.), World Scientific, Singapore, 1994, 417-430.

[4] B. OPIC, A. KufNER, Hardy-type inequalities, Longman, Harlow, 1990. 